OPEN ACCESS

Edited by:

Lu Sun,

National Institute for Environmental

Studies (NIES), Japan

Reviewed by:

Zuoxi Liu,

Shenyang Aerospace University, China

Yi Dou,

The University of Tokyo, Japan

*Correspondence:

Fadwa Eljack

fadwa.eljack@qu.edu.qa

Specialty section:

This article was submitted to

Multi-criteria Decision Making,

a section of the journal

Frontiers in Sustainability

Received: 30 September 2020 Accepted: 18 December 2020

Published: 21 January 2021

Citation:

Eljack F and Kazi M-K (2021) Prospects and Challenges of Green Hydrogen Economy via Multi-Sector

Global Symbiosis in Qatar.

Front. Sustain. 1:612762.

doi: 10.3389/frsus.2020.612762

\section{Prospects and Challenges of Green Hydrogen Economy via Multi-Sector Global Symbiosis in Qatar}

\author{
Fadwa Eljack* and Monzure-Khoda Kazi \\ Department of Chemical Engineering, College of Engineering, Qatar University, Doha, Qatar
}

Low carbon hydrogen can be an excellent source of clean energy, which can combat global climate change and poor air quality. Hydrogen based economy can be a great opportunity for a country like Qatar to decarbonize its multiple sectors including transportation, shipping, global energy markets, and industrial sectors. However, there are still some barriers to the realization of a hydrogen-based economy, which includes large scale hydrogen production cost, infrastructure investments, bulk storage, transport \& distribution, safety consideration, and matching supply-demand uncertainties. This paper highlights how the aforementioned challenges can be handled strategically through a multi-sector industrial-urban symbiosis for the hydrogen supply chain implementation. Such symbiosis can enhance the mutual relationship between diverse industries and urban planning by exploring varied scopes of multi-purpose hydrogen usage (i.e., clean energy source as a safer carrier, industrial feedstock and intermittent products, vehicle and shipping fuel, and international energy trading, etc.) both in local and international markets. It enables individual entities and businesses to participate in the physical exchange of materials, by-products, energy, and water, with strategic advantages for all participants. Besides, waste/by-product exchanges, several different kinds of synergies are also possible, such as the sharing of resources and shared facilities. The diversified economic base, regional proximity and the facilitation of rules, strategies and policies may be the key drivers that support the creation of a multi-sector hydrogen supply chain in Qatar.

Keywords: hydrogen economy, Urban industrial symbiosis, climate change mitigation, multi-sector supply chain mapping, integrated hydrogen production

\section{INTRODUCTION}

Hydrogen $\left(\mathrm{H}_{2}\right)$ economy can play a significant role not only in the global energy mix but also mitigating the impacts of global warming. Addressing this dual challenge requires a collective effort-politicians, business leaders, technologists and consumers-to take careful and meaningful action. Global $\mathrm{H}_{2}$ production is around 70 million tons per annum (MTPA). And it is mainly produced from natural gas and coal; Energy Information Administration (EIA) report shows that $7 \%$ of natural gas is dedicated to the production of $\mathrm{H}_{2}$ (IEA, 2019a). It is predominately used for the production of value-added products such as methanol, ammonia, gas-to-liquids (GTL) fuels, and in refining and steel production. Hence, $\mathrm{H}_{2}$ is a major intermediate in industry. But only around 6\% of the produced $\mathrm{H}_{2}$ is for pure $\mathrm{H}_{2}$ demand, which indicates that it has a limited role in the global energy mix (see Figure 1). Although $\mathrm{H}_{2}$ is key for the production of the value-added products, 


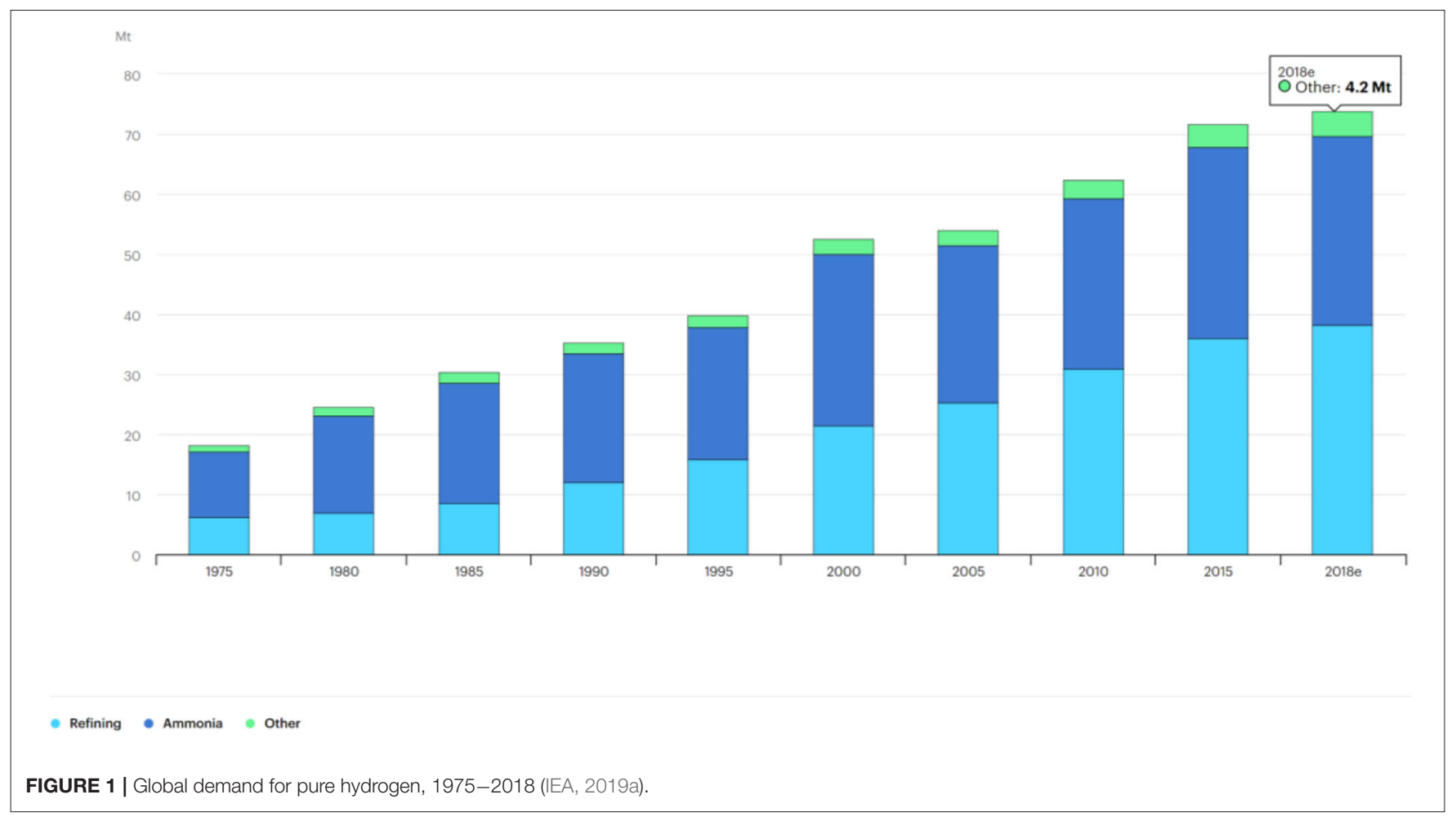

the challenge with Hydrogen is traditionally it is produced through fuel-based schemes such as methane reforming, coal and biomass gasification, all of which lead to carbon emissions and other greenhouse gases.

The necessary shift of today's global markets toward a sustainable future, $\mathrm{H}_{2}$ can play a key role when it comes to decarbonize the energy, industrial and transportation sector. The energy outlook scenarios for 2050 are focused on meeting the Paris Agreement's targets of keeping the earth's temperature rise below 1.5-2.0 degrees Celsius. And those scenarios have $\mathrm{H}_{2}$ playing a bigger role in world's energy mix (IEA, 2019b). It is projected that ten time the current production capacity of $\mathrm{H}_{2}$, nearly $600 \mathrm{MTPA}$ is necessary to meet the carbon neutral targets for 2050, see Figure 2 (Hydrogen Council, 2017).

According to the Hydrogen Council, a United Nations entity under the World Economic Forum, Hydrogen is projected to contribute greatly to the transportation sector (around 150 MTPA), industrial sector (around 110 MTPA), followed by power generation (around $140 \mathrm{MTPA}$ ), and others. Hence, large scale production of $\mathrm{H}_{2}$ from cleaner sources is essential to meet the rising demand for $\mathrm{H}_{2}$ in transportation and all sectors. The International Maritime Organization (IMO), a United Nations

Abbreviations: ATR, Auto-thermal reforming; CAPEX, Capital expenses; CHOSYNs, Carbon-Hydrogen-Oxygen Symbiosis Networks; CO, Carbon monoxide; CO2, Carbon dioxide; EIA, Energy Information Administration; FCEV, Fuel cell vehicle; GTL, Gas-to-liquid; H2, Hydrogen; HSCN, Hydrogen supply chain network; HSCND, Hydrogen supply chain network design; LCOE, Levelized cost of energy; LFL, Lower flammability limit; LNG, Liquefied natural gas; MTPA, Million tons per annum; NG, Natural gas; OPEX, Operating expense; O2, Oxygen; POX, Partial oxidation; PV, Photovoltaics; SR, Steam reforming. agency, has set targets to reduce its greenhouse gas emission by $50 \%$ in 2050 compared to the 2018 baseline emissions. In order to achieve these targets, they mandated a shift from dependence on fossil fuels to an energy mix in the shipping sector that includes low carbon emitting fuels (see Figure 3) (DNV GL, 2017). Green $\mathrm{H}_{2}$ is considered as a carbon-neutral fuel. Qatar has recently submitted an application to join IMO, which indicates their commitment to a sustainable future (Gulf Times, 2018). Japan, US, and EU have already started programs to integrate the use of $\mathrm{H}_{2}$ in the shipping sector. Gray $\mathrm{H}_{2}$ will not be a an option to reduce carbon emission in this sector due to an estimated $\mathrm{CO}_{2}$ emission of 90 grams per Mega Joule (considering well to ship), which is higher the traditional fuels used (DiRenzo, 2019). Hence, there is a need to study economic feasibility and the potential emission reductions association with blue or green $\mathrm{H}_{2}$ for shipping fuel in the sector.

Recent drops in electricity prices from renewables (such as solar and wind), indicates that up to $30 \%$ reduction in production costs can be expected within the decade (IEA, $2019 b)$. At lower cost of renewable energy, its integration is key to making economic and sustainable (low emission) process for "green" $\mathrm{H}_{2}$ production; specifically, the market has shown considerable reduction in the production costs of power from renewables, "green power." Figure 4 shows the global weighted-average levelized cost of energy (LCOE) of utility-scale solar PV declined by 77\% between 2010 and 2018, from USD 0.371 to USD $0.085 / \mathrm{kWh}$ (IRENA, 2019). In addition, the expanding electrolysis capacity that is forecasted will have another added impact in reducing the production costs of green $\mathrm{H}_{2}$. 


\section{Hydrogen demand could increase 10 -fold by 2050}

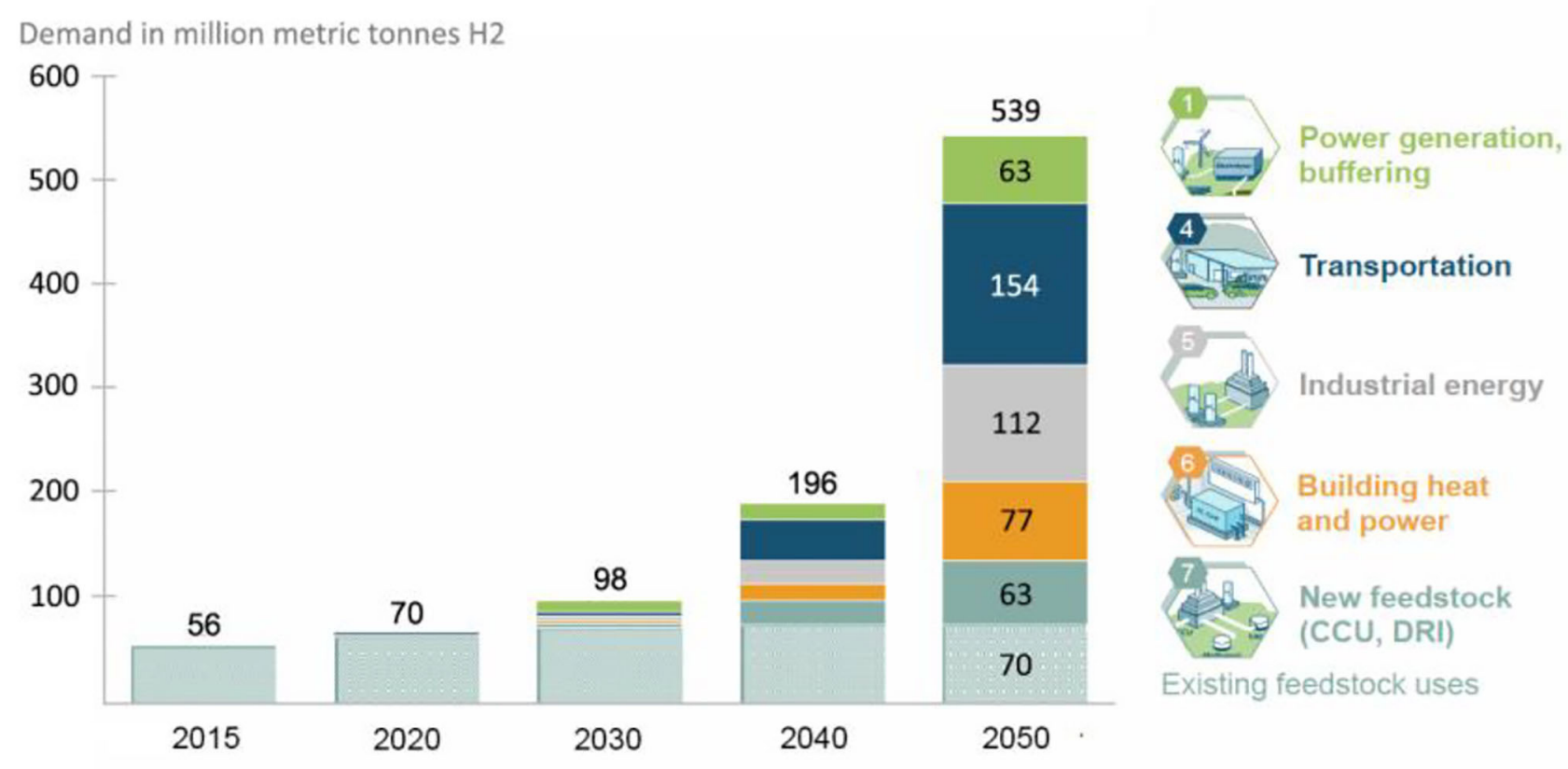

Adapted from Scaling Up, Hydrogen Council, 2017. Orginal units in EJ converted to tonnes $\mathrm{H} 2 ; 1 \mathrm{EJ}=7,000,000$ tonnes $\mathrm{H} 2$.

FIGURE 2 | Global hydrogen demand projection (Hydrogen Council, 2017).

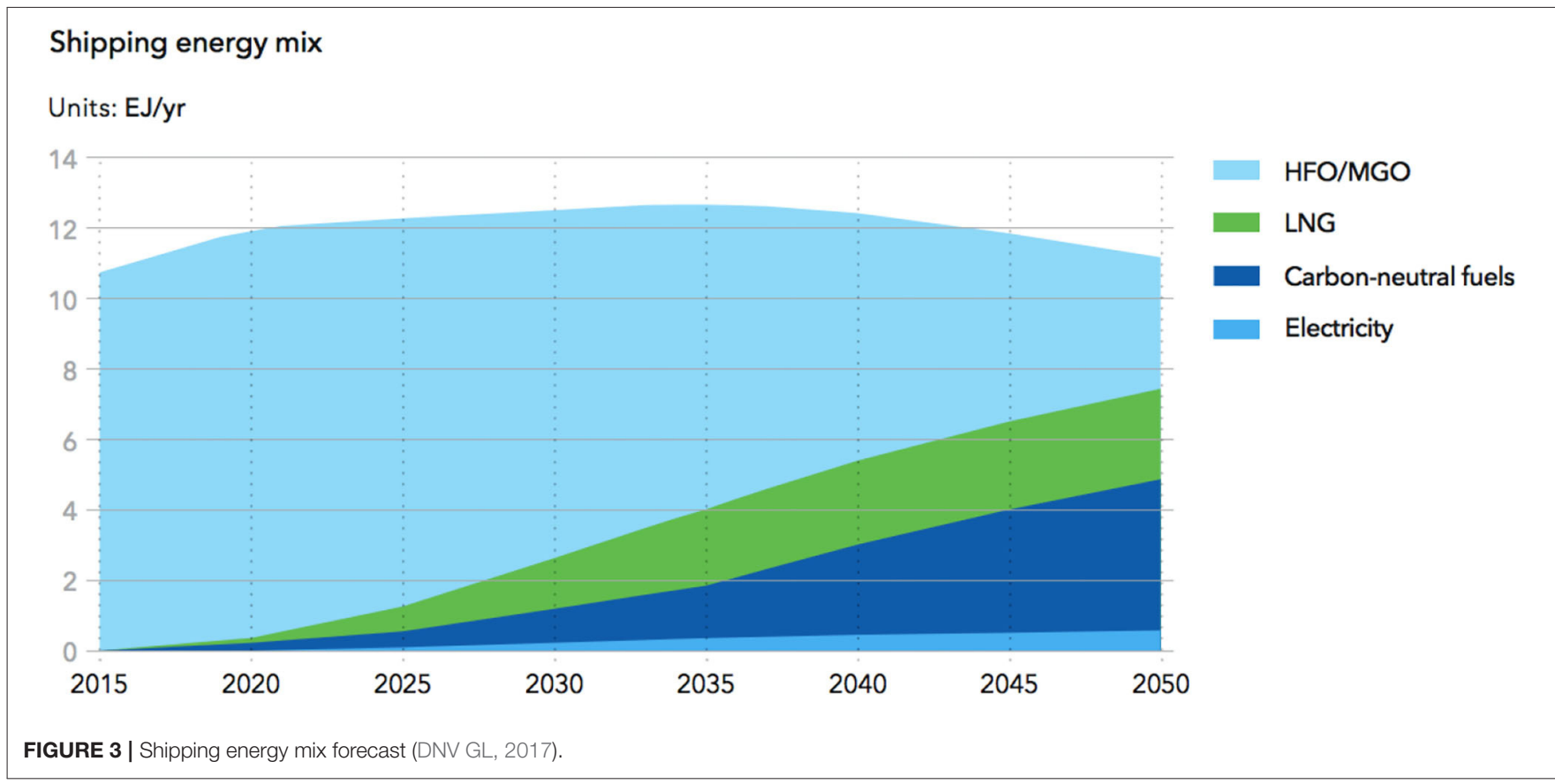

Globally, Japan has initiated a $\mathrm{H}_{2}$ plan back in 2014 and has developed strategies for $\mathrm{H}_{2}$ supply chain to decarbonize its transportation sector. As part of the supply chain, they will import $\mathrm{H}_{2}$, see Figure 5 (Kawasaki, 2019). Perhaps for Qatar, the challenge in decarbonizing its transportation sector will be in the infrastructure investment needed, however Qatar has the capability to produce its own $\mathrm{H}_{2}$ fuel and maybe the potential to export $\mathrm{H}_{2}$ to other economies. Qatar was a pioneer when it ventured into the natural gas (NG) market and LNG supply chains; which made a huge shift in the global energy market. 


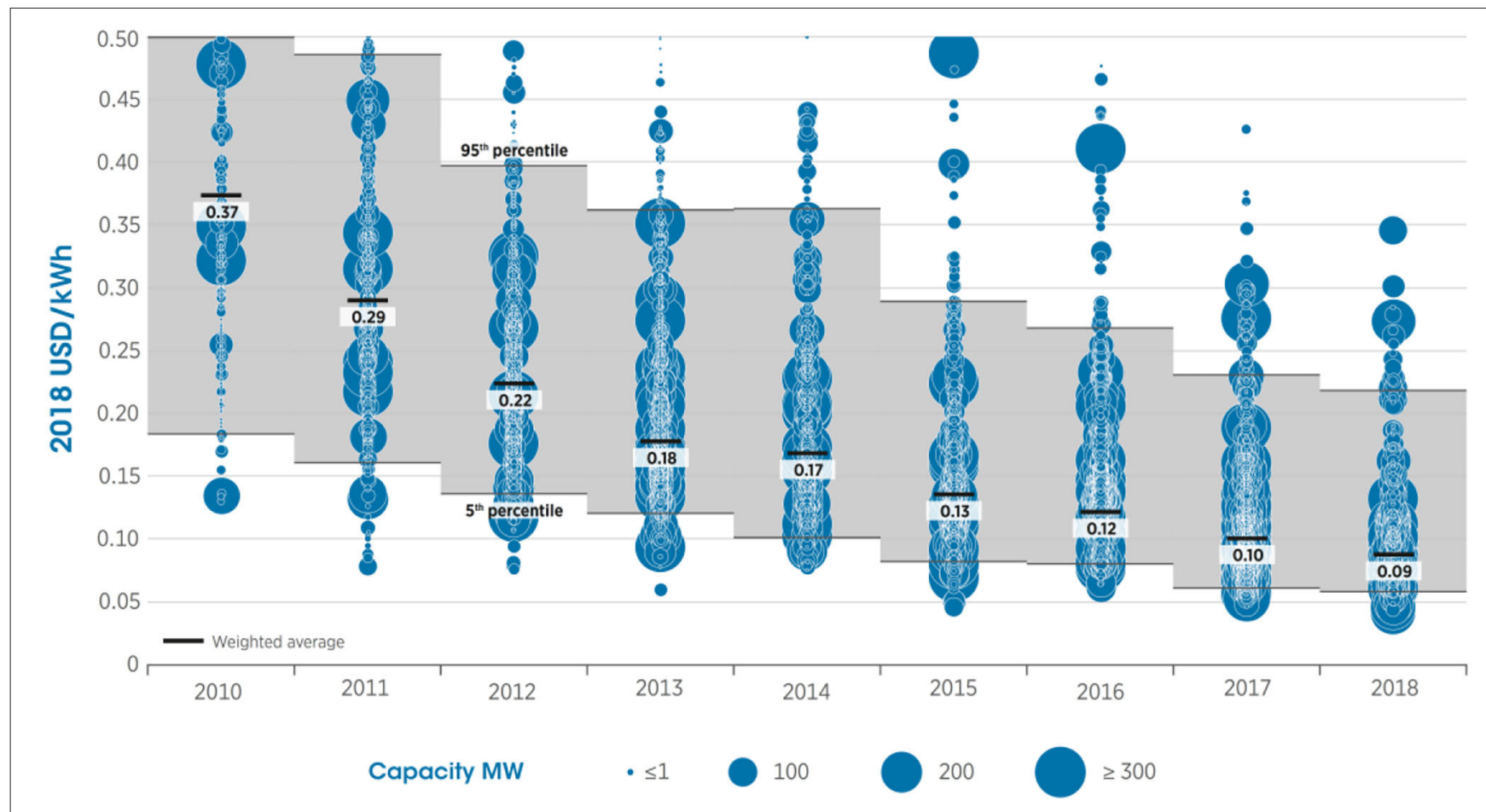

FIGURE 4 | LCOE from utility-scale solar PV projects, global weighted average, and range, 2010-2018 (IRENA, 2019$).$

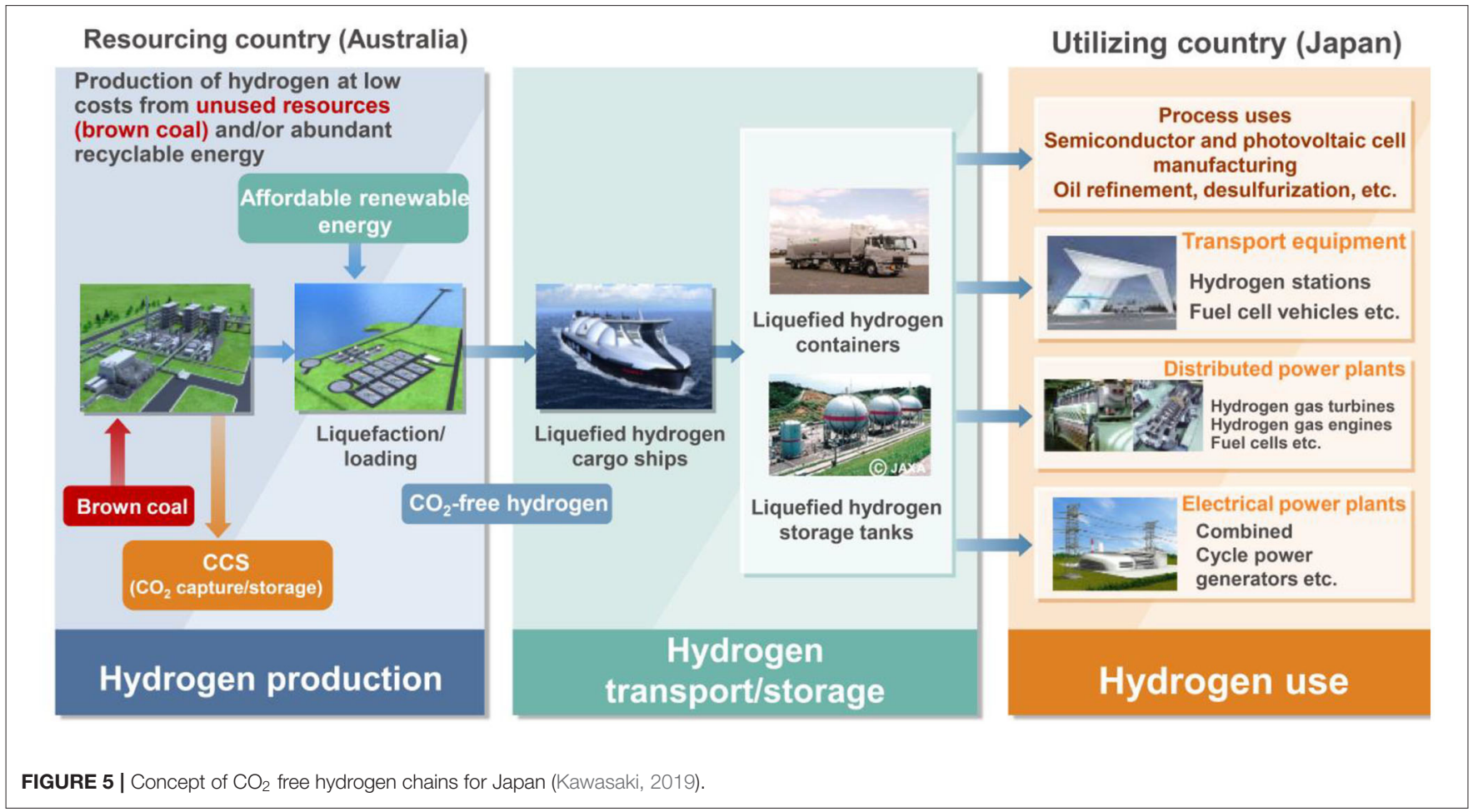

Currently, it is one of the largest exporters of cleaner energy to the world. Qatar has already invested in the renewable markets and has set targets to increase its renewable energy share of the energy mix as part of its Second National Development Strategy 2018-2022 (QSNDS, 2018). It has committed to build large scale solar power facility with a capacity of 800 MW (Peninsula, 2020), 
as part of sustaining their natural gas resources, reduced carbon emission and as part of fulfilling their commitment toward a carbon neutral event "the 2022 World Cup."

The development of optimized $\mathrm{H}_{2}$ supply chains in Qatar entails developing integrated $\mathrm{H}_{2}$ production systems that are economical and that leverage Qatar's available natural gas resources. The intended $\mathrm{H}_{2}$ supply chain network in Qatar will not exist by itself, there are natural synergies with the existing natural gas supply chain. And it is expected that link between these two supply chains will help $\mathrm{H}_{2}$ to overcome the technical performance challenges as such energy efficiency, and the high production costs. If the practicality and feasibility of $\mathrm{H}_{2}$ as transportation fuel is established for small, heavy vehicles and shipping sectors in Qatar; this means a great opportunity for the country to decarbonize its industrial and energy sector and greatly reduce its Greenhouse gas emission. Hence, Qatar's air quality will be improved. The use of green or blue $\mathrm{H}_{2}$ for the production of value-added products in Qatar will contribute greatly to growing Qatar's industrial portfolio. $\mathrm{H}_{2}$ can be used as intermediate to produce a wide range of value products such as GTL, methanol and other petrochemicals, and the project will develop the optimum supply chains for such value-added products. Furthermore, the strategic policies, and investments are needed to support $\mathrm{H}_{2}$ to taking a bigger role in the world's energy mix for a greater implication on a global scale. This strategic step will help Qatar take the lead in becoming a global $\mathrm{HUB}$ for $\mathrm{H}_{2}$. It can become the $\mathrm{H}_{2}$ capital of the world. Therefore, the objective of this paper will be to highlight the state-of-art, perspective and recommendation on hydrogen economy for developing $\mathrm{H}_{2}$ supply chain mapping for Qatar's Industrial, Transportation, Shipping and Global Market Sectors in order to leverage the tradeoffs and to maximize the production of $\mathrm{H}_{2}$ as a clean energy source with a bigger role in the energy mix.

The perspective of this paper mainly focusses on the road toward the realization of a $\mathrm{H}_{2}$ based economy by the addressing the following key points:

1. Inclusion of hydrogen in global energy mix.

2. Safety aspects related to hydrogen production, storage, and transportation in multi-sectors.

3. Understanding the symbiotic relationship between ecoindustrial park and hydrogen production.

4. Development of multi-sector hydrogen supply chain mapping.

5. Impacts of intemporal changes in hydrogen prices/demand/global markets.

6. Role of policies in support of a multi-sector global hydrogen economy.

\section{STATE OF THE ART, PERSPECTIVE, AND RECOMMENDATION ON HYDROGEN ECONOMY}

\section{Inclusion of Hydrogen in Global Energy Mix}

All major energy outlook scenarios show that $\mathrm{H}_{2}$ and renewable energy resources will be the main drivers toward global reductions of greenhouse gas emissions. In a report from
Norwegian classification company DNV GL, the priority list of many oil and gas organizations has been raised by hydrogen as it works to decarbonize the sector. The analysis states that half senior oil \& gas professionals expect hydrogen to play a major role in the energy mix by 2030, and that, despite recent oil shocks, it is time that the hydrogen economy began to escalate (Bulletin, 2020). Yet, the role of $\mathrm{H}_{2}$ in today's energy mix is nowhere to be seen; the main challenge is in the production costs associated with $\mathrm{H}_{2}$ from renewable sources; that is $\mathrm{H}_{2}$ production systems that result in near zero to low carbon emission. Existing $\mathrm{H}_{2}$ production routes are via combustion of fossil fuel-based feeds (coal, NG, etc.) that generate high amounts of $\mathrm{CO}_{2}$. For Qatar, $\mathrm{H}_{2}$ can become a major player in diversifying its energy mix, expanding its industrial supply chain profile and reducing its environmental footprint. The use of $\mathrm{H}_{2}$ as clean energy source is limited mainly due to the emission produced from the existing hydrocarbon-based production routes such as steam reforming (SR), partial oxidation (POX), and autothermal reforming (ATR). The advancement of green hydrogen production technologies like electrolysis have offered a cleaner alternative for $\mathrm{H}_{2}$ production; yet critics are quick to state that although the production generates "green" $\mathrm{H}_{2}$ and $\mathrm{O}_{2}$, the process is energy intensive. Hence overall, the process is not emission neutral, unless the use of alternative renewable sources is considered to reduce the energy penalties. Another challenge is the higher production costs for green technologies such as electrolysis (green $\mathrm{H}_{2}$ ) are relatively high compared to established $\mathrm{H}_{2}$ production systems (gray $\mathrm{H}_{2}$ ). Table 1 shows that $\mathrm{H}_{2}$ production via electrolysis $\left(\$ 10.3\right.$ per $\left.\mathrm{kg} \mathrm{H}_{2}\right)$ is 5 times that of established technologies ( $\$ 1.5-2.3$ per $\left.\mathrm{kg} \mathrm{H}_{2}\right)$. Hence "green" $\mathrm{H}_{2}$ costs are another challenge facing the $\mathrm{H}_{2}$ role in the energy mix (Shiva Kumar and Himabindu, 2019).

\section{Types of Hydrogen}

It should be noted that there are different type of $\mathrm{H}_{2}$, and their classification is based on the source of production (see Figure 6).

- $\mathrm{H}_{2}$ generated from hydrocarbon-free renewable resources or excess process heat via a non-fossil process such as electrolysis of water is "green $\mathrm{H}_{2}$," with very low carbon emissions.

- $\mathrm{H}_{2}$ produced for hydrocarbon sources is classified as "gray $\mathrm{H}_{2}$," where there is associated carbon emission. A majority of the global hydrogen production is gray $\mathrm{H}_{2}$.

- $\mathrm{H}_{2}$ produced from hydrocarbon sources, where the generated carbon emissions are captured or utilized, are considered "blue $\mathrm{H}_{2}$." Hydrogen produced from nuclear is also considered as blue $\mathrm{H}_{2}$ due to the small amount of carbon emissions.

\section{Opportunity of Integrated Hydrogen Production System}

Integrating $\mathrm{H}_{2}$ production within a large-scale industrial complex can benefit the $\mathrm{H}_{2}$ production supply chain. Many tradeoffs that exist within the Industrial sector that can be leveraged while considering integrated hydrogen production system using latest renewable energy technologies. Hydrogen can be produced using diverse resources, including fossil 
TABLE 1 | Different hydrogen production methods, their advantages, efficiency, and cost (Shiva Kumar and Himabindu, 2019).

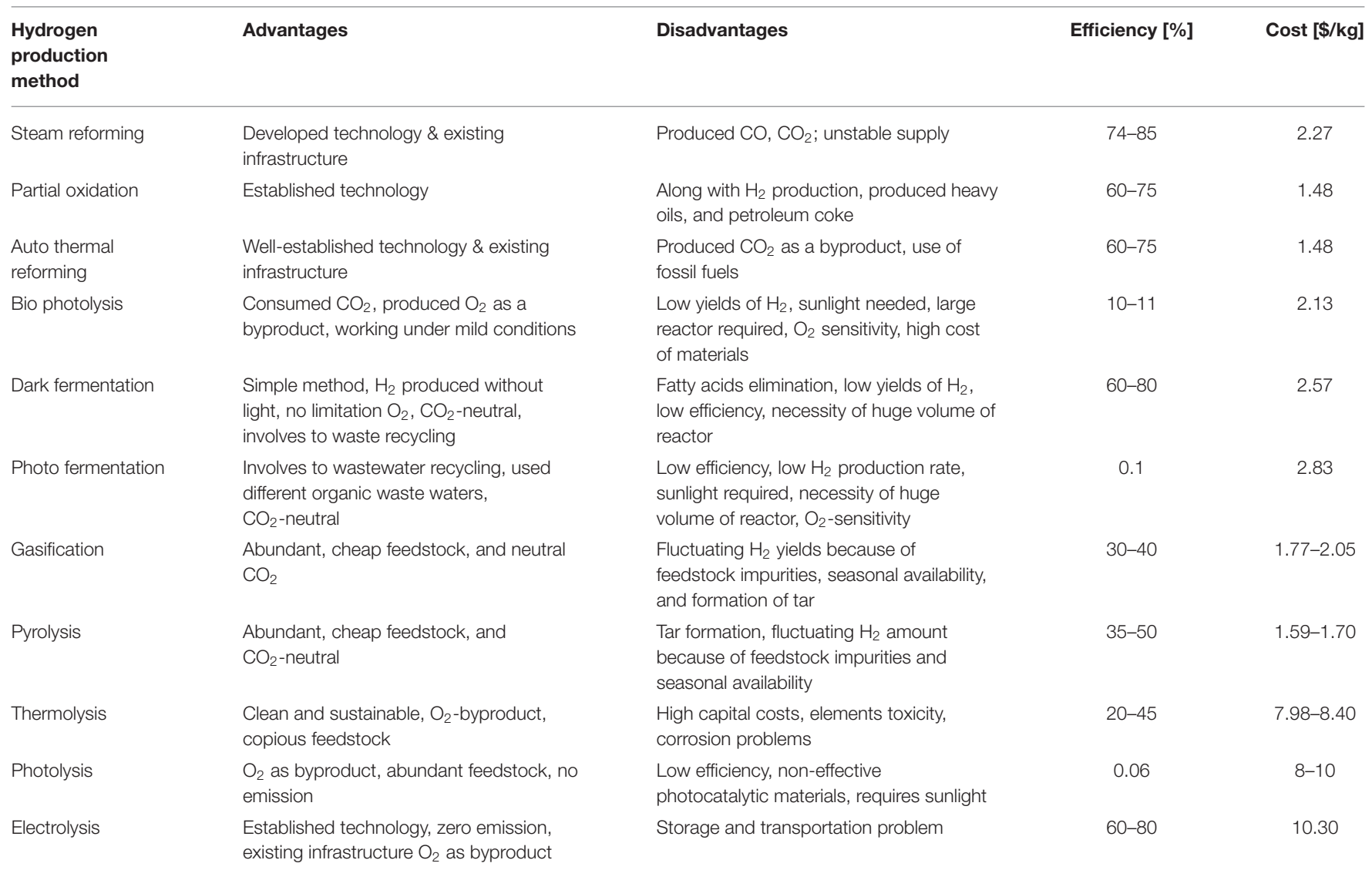

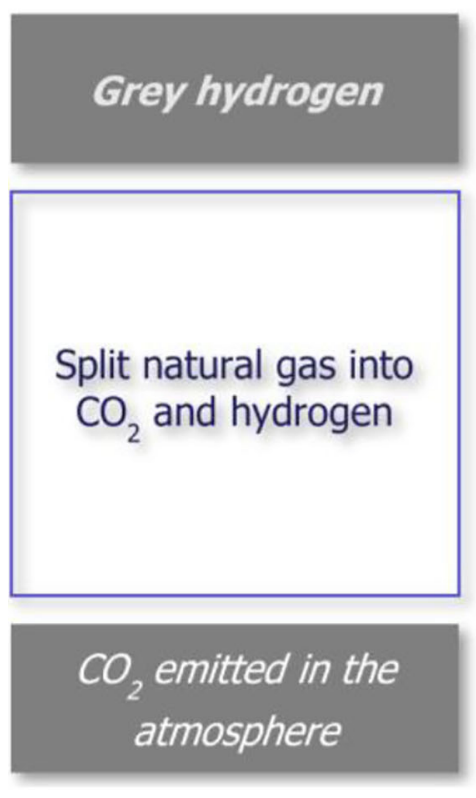

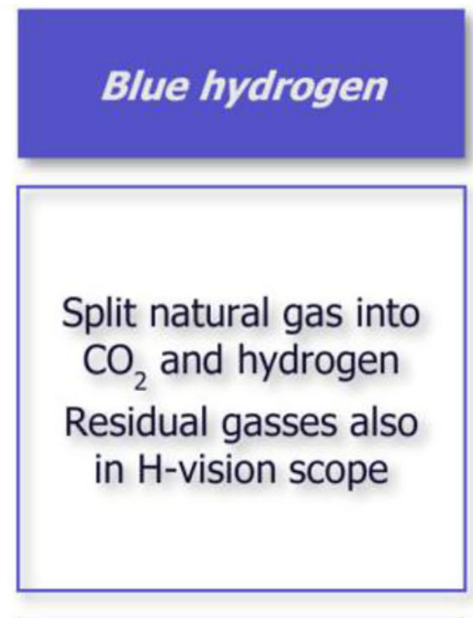

$\mathrm{CO}_{2}$ stored or re-used

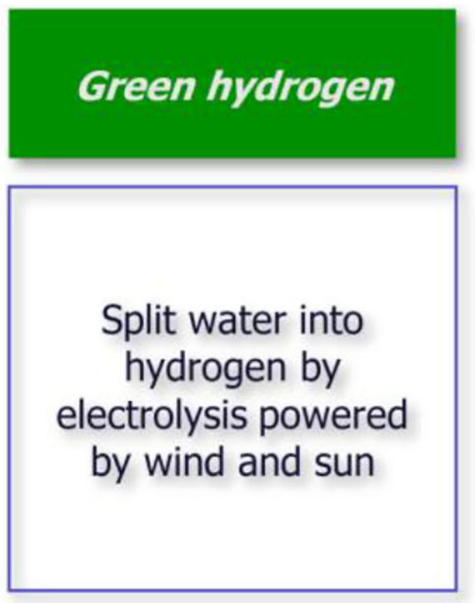

\section{No $\mathrm{CO}_{2}$ emitted}

FIGURE 6 | Types of hydrogen (SINTEF, 2019).

fuels (preferably with carbon capture, utilization, and storage); sustainable biomass, non-food plant; or nuclear and renewable sources of energy (e.g., wind, solar, geothermal, and hydro-electric). This variety of possible sources of supply makes hydrogen such a promising energy source and carrier. Tables 1, 2 display variables such as energy sources, feed stock, 
TABLE 2 | Cost comparison of different hydrogen production methods (Kayfeci et al., 2019).

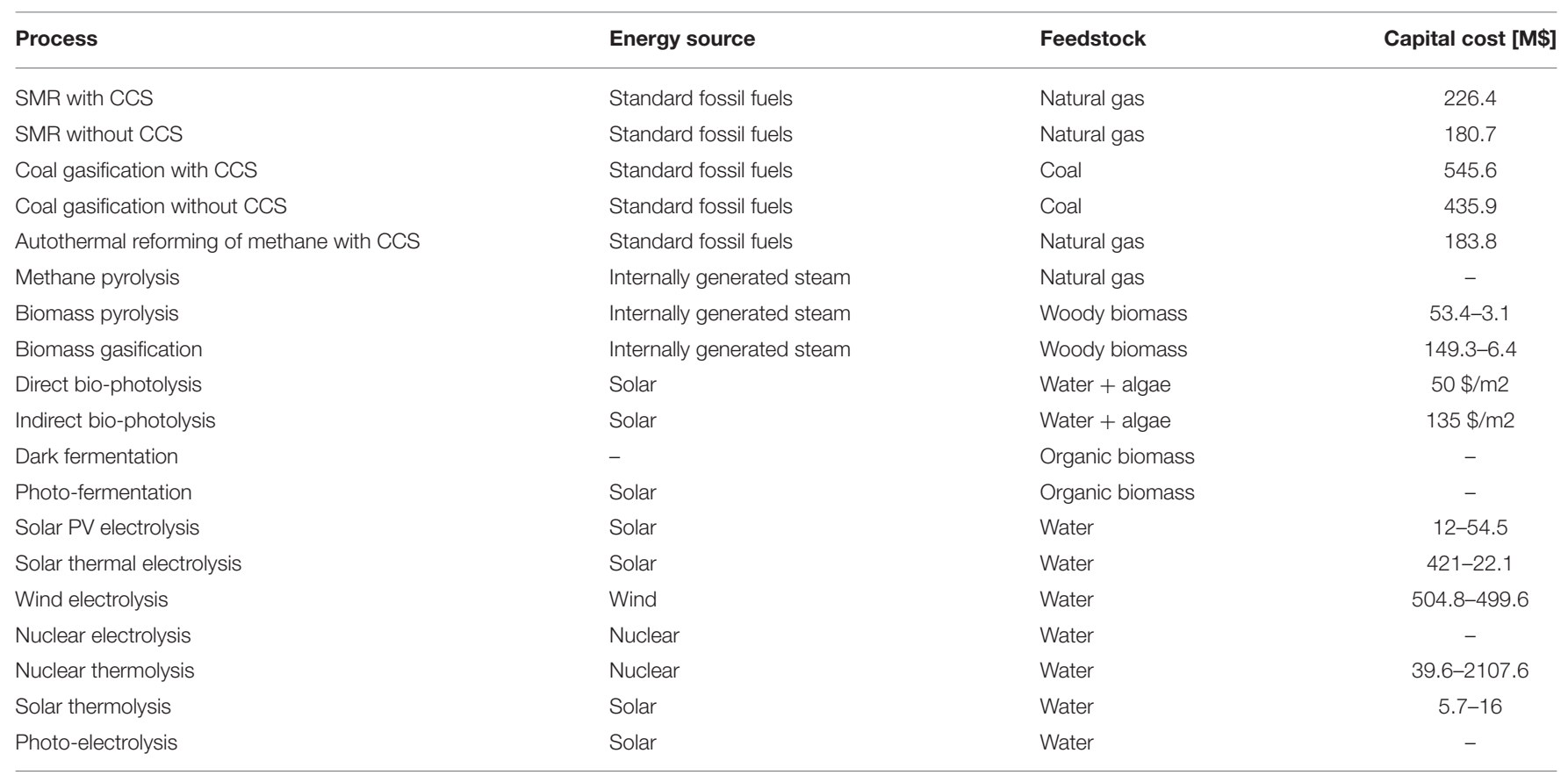

capital expenditure, and hydrogen production cost (per $\mathrm{kg}$ of hydrogen) for qualitative evaluation of the costs of each hydrogen production process.

Hydrogen mostly produced from hydrocarbon-based sources results in high carbon emission (gray $\mathrm{H}_{2}$ ). And although green and blue $\mathrm{H}_{2}$ are considered carbon neutral energy sources, they come at extremely high production costs (see section Inclusion of Hydrogen in Global Energy Mix, Table 1). At present, the hydrogen production using natural gas with the SMR is supposed to be the most cost-efficient alternative, maintaining a low carbon emission level (Moreno-Benito et al., 2017). Techno-economic analysis of large-scale green and blue $\mathrm{H}_{2}$ production systems suggests that there is a clear need of combining renewable energy sources to be competitive with the existing commercial production of gray $\mathrm{H}_{2}$ (Abdin and Mérida, 2019; Armijo and Philibert, 2020; van der Roest et al., 2020). The case will be even more compelling if the carbon tax implementation occurs (Almansoori and Betancourt-Torcat, 2016; Ishaq and Dincer, 2019; Nguyen et al., 2019; Talebian et al., 2019). Therefore, considering new $\mathrm{H}_{2}$ policy and carbon tax can benefit the largescale production of green and blue $\mathrm{H}_{2} \cdot \mathrm{H}_{2}$ can also be used as a promising solution for a multi-sectorial decarbonization as it allows to link between the green and blue $\mathrm{H}_{2}$ production systems and the other energy sectors (industry, transport, and natural gas system) (Burandt et al., 2019; Helgeson and Peter, 2020; Tlili et al., 2020). The production of large-scale green and blue $\mathrm{H}_{2}$ will more energy efficient and economical viable if integrated processes are applied (Gençer and Agrawal, 2017; Lee et al., 2019; Spallina et al., 2019; Mosca et al., 2020).

Recently, an integrated and tunable system for the production of syngas and chemicals via solar-assisted electrolysis and combined reforming have been patented (El-Halwagi and Campbell, 2018). This recent patent by El-Halwagi and Campbell (2018) proposed the harvesting of solar energy and use of electrolysis for the production of hydrogen $\left(\mathrm{H}_{2}\right)$ and oxygen $\left(\mathrm{O}_{2}\right)$ and integrating these products with synthesis gas $\left(\mathrm{H}_{2}\right.$ and $\left.\mathrm{CO}\right)$ and produced from established methane reforming processes (see Figure 7). The system looks to reduce the production cost of electrolysis by integrating with existing large-scale industrial systems and making use of renewable energy. It also demonstrates the value of integrating by-product streams such as $\mathrm{O}_{2}$ in other complimentary industrial systems for the production of value-added products, in this case chemicals. The approach in this integrated "tunable" system for Syngas production shows the value of maximizing the use of by-product or material stream and waste heat recovery in the valorization of $\mathrm{H}_{2}$ production. A similar approach can be used to identify suitable means of integrating renewable energy, electrolysis, and other emerging $\mathrm{H}_{2}$ production systems with existing natural gas processing facilities like those available in Qatar. The challenge will be in the formulation of the optimization problem to synthesize integrated systems for $\mathrm{H}_{2}$ production considering the competing objectives of maximizing the production of green and blue $\mathrm{H}_{2}$ in the hydrogen supply chain network (HSCN).

Qatar has the largest GTL plant in the world, with capacity to produce 280,000 barrels of water as by product of its activities. This could be a potential water source that can be integrated with $\mathrm{H}_{2}$ production through electrolysis. For natural gas-based industry in Qatar, the industrial cities include GTL, LNG, petrochemical large-scale facilities, that can offer opportunities to trade material streams to greatly reduce the $\mathrm{H}_{2}$ production cost by integrating them in the considered industrial facilities. There 


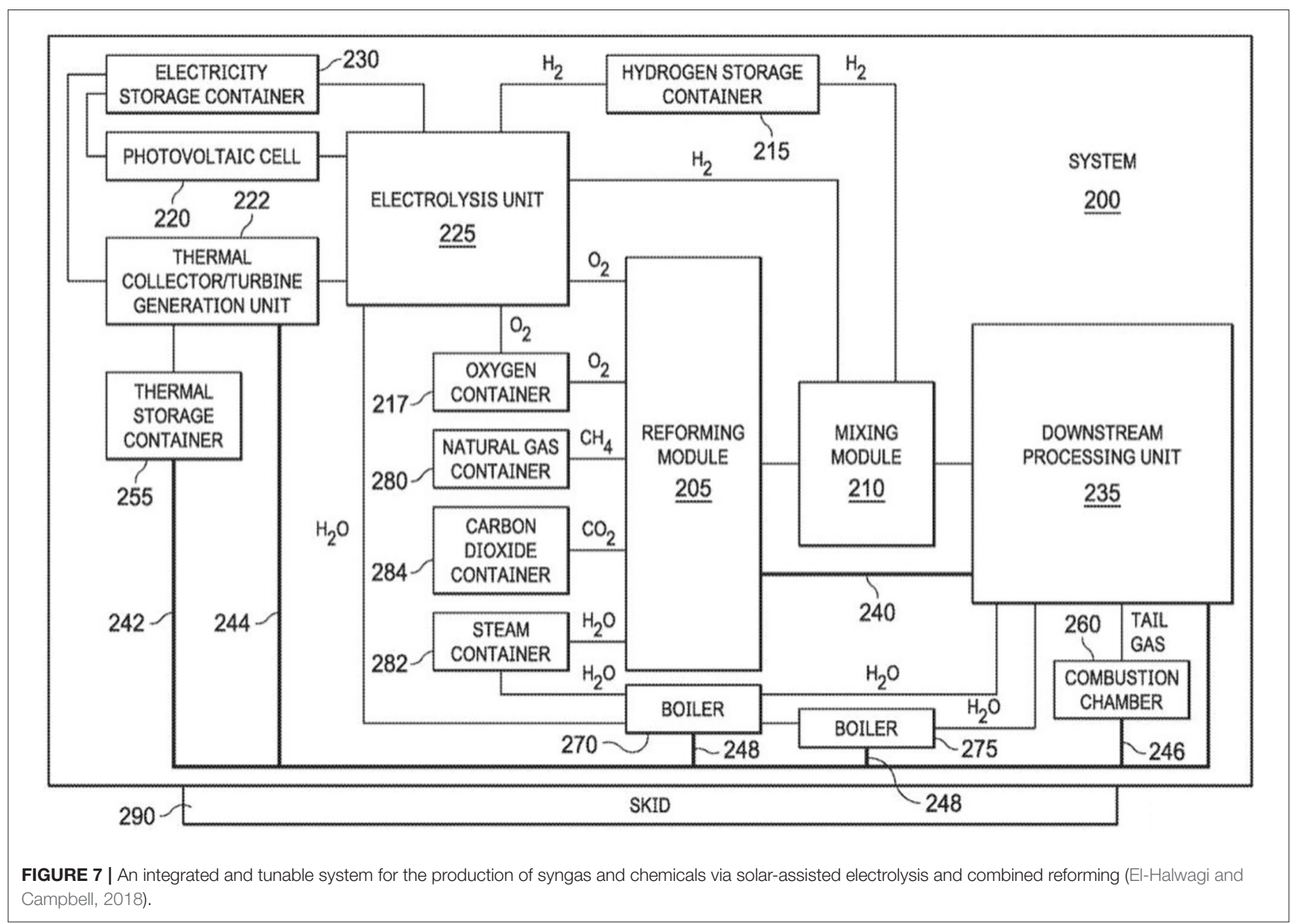

will be many facets while considering the integrated hydrogen production complex with those industries which can generate mutual benefits. Such as:

- Industrial energy efficiencies will be improved by utilizing the waste energy streams for the $\mathrm{H}_{2}$ generation.

- Produced water by-products can be utilized as the media of $\mathrm{H}_{2}$ production.

- The efficiencies and carbon emission performance of $\mathrm{H}_{2}$ production system will be enhanced by the utilization of the excess material and energy streams from the industries.

- Intermediate produced hydrogen can be linked up with the $\mathrm{H}_{2}$ production facility if appropriate integration of the process is achieved.

However, the possible integration of the industrial processes should be considered in such a manner that the upscaling of the $\mathrm{H}_{2}$ production system and the transportation of the produced hydrogen to end uses should be feasible and sustainable. There is a need to determine the suitable insertion point(s) for $\mathrm{H}_{2}$ supply chains within the natural gas supply chain in Qatar. As stated earlier, hydrogen is a commodity that can be used as fuel for energy or as feedstock to produce large spectrum of valueadded products, see Figure 7 (The Maritime Executive, 2018). The insertion point is the link point where the two supply chains cross. For example, use of $\mathrm{H}_{2}$ a fuel in the industrial sector or the recovery of carbon emissions and integrating them within the industrial section for the production of ammonia, these can be potential insertion points for the two supply chains. $\mathrm{H}_{2}$ network in reality is cross linked with NG supply chains, and its realization will help decarbonize the industrial sector and sustain natural gas for value added product. Integration of $\mathrm{H}_{2}$ supply chain within the industrial sector gives a higher potential for making $\mathrm{H}_{2}$ as a clean energy source as a reality.

\section{Safety Aspects Related to Hydrogen Production, Storage, and Transportation in Multi-Sectors \\ Perception About Hydrogen Safety}

Hydrogen is an ideal energy source and chemical feedstock because of its high energy content and relatively low environment impacts. In working with hydrogen, as happens with all gases, it is essential to learn about its physical, and chemical properties in order to know its behavior and possible associated risks. Nevertheless, the perceived high risk associated with hydrogen by society is an important challenge that must be addressed before any widespread use can be achieved. There are also preset notions regarding the safety of $\mathrm{H}_{2}$ when it comes to storage and 
transportation that are very similar to the concerns raised in the early days of the development of LNG supply chain.

Hydrogen is not very distinct from other flammable and fuel gases in many ways (Schmidtchen, 2009). The low minimum ignition energy of the mixture with air is a distinctive feature of hydrogen. This is less risky than it seems. Hydrogen is a flammable gas with a wide flammability range $(4-75 \%$ by volume) and relatively low ignition energy (0.02 millijoules) (Schmidtchen, 2009). It has an extremely low density and must therefore be kept at high pressure (range 10,000-15,000 psi) to produce a sufficient mass for practical application (Dawood et al., 2020). In case of leaks, it was found that $\mathrm{H}_{2}$ fuels are safer than hydrocarbon-based fuels such as gasoline, because they rise rapidly and dissipate quickly into the atmosphere, limiting their possibility of igniting (Pozzi, 2017). However, hydrogen is not toxic and much lighter than air and disappears quickly, allowing the fuel to disperse relatively rapidly if the fuel leaks, making it more secure than other spilled combustibles. The primary security problem is that if a leak is unidentified and the gas collects in a confined area, it can eventually set fire to an explosion (Dawood et al., 2020). Hydrogen fire sensors usually work by ultraviolet or infrared sensors, as generally hydrogen fires do not emit visible light. The fire detectors are state-of-the-art, costly, and can be vulnerable to false alarms. It is evident, that hydrogen can be managed safely by knowing and appreciating its physical properties by people using gas and taking adequate precautions when considering movement between multi-sectoral systems. The design standardization, codes, and regulations on hydrogen will play a significant role in ensuring that safeguards are in place to protect users, staff, the community, and the environment from the effects of hydrogen events. These safeguards can be enforced by frequent inspections and maintenance of facility.

\section{Recent Studies on Hydrogen Safety}

Edelia et al. (2018) studied the effects of unconfined hydrogen releases using the simulation software FLACS for calculating the potentially explosive fluid dynamics. They identified that when the leak source is close to the ground and the initial gas pressure and release rate are significantly higher, lower flammability limit (LFL) will increase in hydrogen flammable gas cloud. Therefore, it's advisable to take a free flow release during dangerous studies if hydrogen leak sources are close to the ground (Edelia et al., 2018). With computational fluid dynamic computer codes, the modeling of gas releases and gas blending in enclosures is increasingly comprehensive (Han et al., 2018). Interestingly, in the recent past, some records have been made of hydrogen fires and deflation. Some of these accidents are due to the lack of knowledge of cylinders or piping operating with gas, lack of understanding of the existence of hydrogen gas, or incorrect monitoring of the hydrogen in process equipment (Mirza et al., 2011). Other incidents are actually due to a malfunction of equipment close to a sufficient source of ignition.

\section{Safety Challenges in Hydrogen Storage and Transportation}

Safe, compact, light, and cost-effective hydrogen storage is one of the keys to hydrogen economic growth. Liquid and compress $\mathrm{H}_{2}$ are at cryogenic temperatures and hence the safety impacts of their release in air need to be considered during the supply chain network synthesis. Hydrogen is also able to attack, and damage certain materials used to build storage containers, pipes, valves, and other equipment at the point of leakage. Sometimes this destructive ability is referred to as hydrogen embrittlement (Phull, 2003). However, technoeconomic feasibility of hydrogen storage systems is yet to be realized as none of the current conventional gaseous, liquid, and metal hydrides fulfill all the essential criteria for a practical hydrogen economy, mainly because of safety, cost problems, low hydrogen storage capacity, sluggish kinetics, and unacceptable temperatures of hydrogen absorption/desorption (Abe et al., 2019). Hydrogen gas detectors are required to secure indoor spaces just as natural gas detectors are generally recommended for repair garages and other buildings in the standardized fire code.

Hydrogen is a technically promising fuel for transportation. Research and testing results are good until now. The combination of hydrogen and fuel cell technology in particular ensures low emissions for cars, buses, forklift trucks and other vehicles. Although very tragical and infamous hydrogen-related accidents have taken place, the hazards, and phenomena are now well-known and well-understood. Knowledge about hydrogen physical properties has increased, including accident modeling and prediction (Al-shanini et al., 2014; Zhang et al., 2018). An example of the improvement in awareness is that the 1937 Hindenburg airship crash study reported a low level of 62-66 percent of the upper flammability limit for hydrogen in air, which is considered to be 74 percent. Nonetheless, hydrogen use has expanded to over 8 million tons annually as a chemical reagent and rocket propellant. Some research indicate that hydrogen vehicles are less dangerous than petrol vehicles in enclosed environments, with fuel spills contributing to a greater flammable gas cloud (Lasn and Echtermeyer, 2014). Hydrogen burns with little fuel, so that nothing will burn unless it is next to the flame immediately (Lasn and Echtermeyer, 2014; Singh et al., 2015). Another safety benefit is that a transparent flame is not capable of melting skin due to the minimal heat radiation released by the flame due to the lack of soot material.

\section{Understanding the Symbiotic Relationship Between Eco-Industrial Park and Hydrogen Production}

Hydrogen production facility will be an integral part of the eco-industrial park. Available excess resources (i.e., renewable energy, excess heat, water, intermediates, and by-products, etc.) of other industries can be integrated with the hydrogen production facility which can reduce the overall footprint as well as the hydrogen production cost (Kazi et al., 2015, 2016, 2017; Eljack and Kazi, 2016). The hydrogen production cost has some uncertainties, which is greatly influenced by the developments in production technology, current infrastructure availability, and feedstock prices. Besides, rising industrialization and urbanization, energy and resource intensive use, and land use patterns are some challenging factors for any standalone 
hydrogen production facility. As a subset of industrial ecology, industrial symbiosis can help solve these problems without compromising economic development through more efficient use of resources. For instance, decision-makers should construct a common hydrogen production facility for an eco-industrial park rather than separate hydrogen production facilities. As highlighted in Table 2, various energy source and feed stock can be used for the hydrogen production. These energy/resources can be obtained/produced from the nearby industries using shared facility. Such as discharge water from any industry can be the potential source of electrolysis, if the quality of the water is enough after the wastewater treatment facility.

Hydrogen can be generated at large central plants, in medium-sized semi central plants or at or very close to the point of operation in small dispersed units such as refueling stations or stationary power stations. This also give the leverage to the decision makers sizing their hydrogen production plant within the eco-industrial park based on the demand pattern from the various downstream sectors (i.e., demand from industry, urban transportation, shipping fuel, or global trading side). The environmental benefits of industrial symbiosis in hydrogen economy should be quantified by measuring the changes in consumption of natural resources, and in emissions to air and water, through increased circular use of materials and energy (Kazi et al., 2015, 2016, 2018; Al-Nouss and Eljack, 2019). Whereas, the economic benefits should be quantified by how well companies can collect revenue streams or reduce disposal costs by gaining advantage of receiving byproducts, avoiding transportation fees or obtaining inputs at a discount. It should be noted that in certain situations, there are less direct benefits from collaborating with neighbors, but it may have some other benefits, such as enhancement in credibility, and facilitation of the permit.

Multi-sector HSCN also considers international export (Global Market Sector). The demand contribution from this sector can play a major role in economic viability of large scale $\mathrm{H}_{2}$ production and the deployment of $\mathrm{H}_{2}$ as competitive clean energy source. In Qatar, determining the insertion point that links the HSCN with the existing NG supply chain will be crucial. This consideration is expected to determine the potential for $\mathrm{H}_{2}$ production to decarbonize the Industrial sector. Recognizing the natural symbiotic relationship between the two sectors is important for the Qatari case and is unique compared to all other works in the literature. Msakni and Haouari (2018) investigated the supply chain of Liquefied Natural Gas (LNG). They considered a complex planning problem that involves scheduling a heterogeneous vessel fleet with controllable cruising speeds, while accommodating numerous realistic technical constraints including time windows, berth capacity, and storage capacity. They developed a polynomialsized formulation as well as an effective metaheuristic. In this regard, Al-Haidous et al. (2016) developed a mixed-integer integer programming formulation for optimizing the number of cryogenic vessels that are requested for delivering LNG cargoes. Furthermore, Salem and Haouari (2017) investigated a threeechelon supply chain network design problem, where both the supply and the demand are stochastic. Domínguez-García et al.
(2017) developed an optimization framework for the strategic planning of jet fuels that involve the production and use of green hydrogen. Qatar is poised to play a critical role in the creation of such novel supply chains with synergistic integration of renewable and natural gas resources. The problem requires selecting suppliers, warehouse locations and sizing, as well as the material flows. They solved this problem by developing a novel hedging strategy that was implemented using a particle swarm optimization approach (Domínguez-García et al., 2017).

\section{Development of Multi-Sector Hydrogen Supply Chain Mapping and Optimization}

Multi-sector hydrogen supply chain network (HSCN) mapping and optimization can play essential role to realize fruitful hydrogen economy-based society in future but it has not been addressed in the literature intensely. The overall approach looks to model HSCN using a five-layered network that captures all the supply chain stages, more precisely, the first layer includes all the primary feedstock nodes (natural gas, waste stream, water, solar energy, and waste heat). The second layer includes some secondary feedstock nodes (solar electricity, solar heat, and electricity from the power grid). The third layer includes all the production nodes (electrolysis, steam reforming, POX reforming, dry reforming with utilization of $\mathrm{CO} 2$, and emerging systems). The fourth layer includes all the storage nodes (compressed hydrogen, liquid hydrogen, and liquid $\mathrm{H} 2$ carriers). Finally, the fifth layer includes all demand nodes where each demand node refers the aggregated demand of a specific sector (transportation, industrial, shipping, and global market). See Figure 8 for the detail mapping with the identified layers for the HSCN modeling.

Currently, HSC optimization has mostly focused on the transportation sector. In literature, the researchers highlighted the importance of $\mathrm{H}_{2}$ as a potential cleaner fuel source in the transportation sector (Ochoa Bique and Zondervan, 2018; Khatri and Khatri, 2020; Oliveira et al., 2020; Zareei and Rohani, 2020). They comprehensively investigated the feasibility of hydrogen as transportation fuel from a supply chain point of view through superstructure modeling to make it viable to replace the fossil fuel (Ochoa Bique and Zondervan, 2018; Talebian et al., 2019; Seo et al., 2020).

But in those HSCN for transportation the following issue were not considered:

- No works addressed the integration of the raw materials for large-scale green or blue $\mathrm{H}_{2}$ production. Whereas, initial works on gray $\mathrm{H}_{2}$ production showed that considering mixing feedstocks can be beneficial for improving the operating profit as well as the energy efficiencies of the process (Ketabchi et al., 2019; Liu et al., 2019).

- Uncertainties from energy and $\mathrm{CO}_{2}$ emission policies, $\mathrm{H}_{2}$ prices, and production costs were not considered in the formulation of HSCN. In the $\mathrm{H}_{2}$ supply chain of the transportation system, works were mostly focused on the uncertainties from demand side only (Kim et al., 2008, 2018; Nunes et al., 2015; Zhou et al., 2019).

- No work has addressed the intertemporal integration of $\mathrm{H}_{2}$ supply chain with any other existing supply chain yet. 


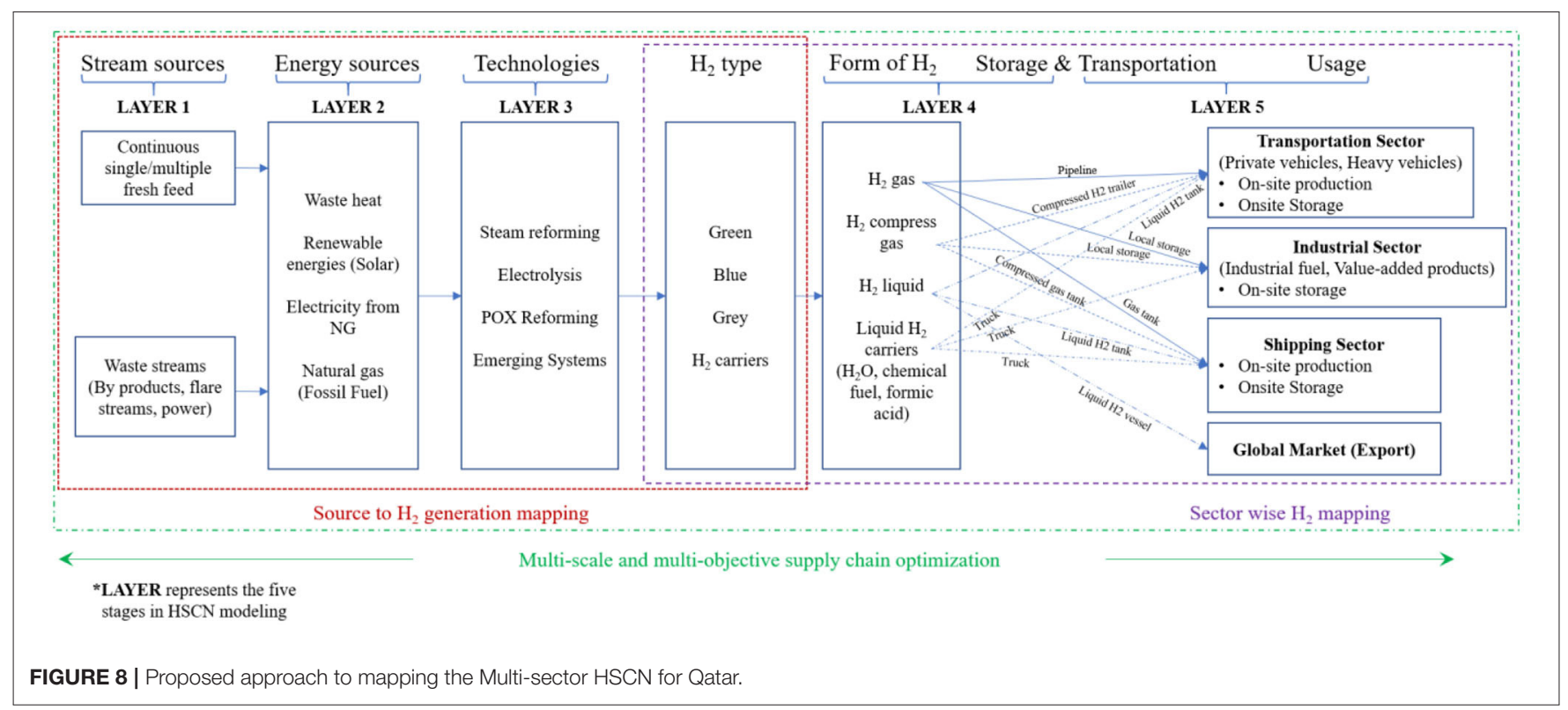

But, Scientific literature highlighted the crucial role of green technology diffusion pathways throughout the supply chain (Costantini et al., 2017).

- Very limited focus has been given for the export-oriented supply chain. Li et al. (2019) stated in their review paper that HSCND models currently focus on hydrogen production with domestic feedstocks. However, they also stressed that the world trade in hydrogen can give exporting and importing countries win-win opportunities, although the long-distance transport of hydrogen trading and multinational and cross-regional financing could become a further problem. Almansoori and Shah have considered the import of feedstock from other countries in their studies but did not consider the global market (Almansoori and Shah, 2009, 2012).

The probable multi-sector HSCN optimization problem should consider the abovementioned research gap in their upcoming multi-sector HSCN for Qatar (see Figure 8). The development of novel tools and formulations for the integration of hydrogen production systems and supply chains can be drawn from the lessons and foundational elements of industrial ecology especially the design and optimization of Carbon-HydrogenOxygen Symbiosis Networks (CHOSYNs) (Noureldin and ElHalwagi, 2015; El-Halwagi, 2017; Al-Fadhli et al., 2019; JuárezGarcía et al., 2019; Panu et al., 2019). The resulting formulation will be a mixed-integer non-linear programming optimization model that can readily include various objectives such as cost, environmental impact, safety, reliability, and resilience.

Although previous work in the literature considered different technologies and feedstocks in the optimization, the generated solutions are single technology production routes, which limits the production scale. Whereas, an integrated $\mathrm{H}_{2}$ production systems for large scale production of gray, green and blue $\mathrm{H}_{2}$ with the objectives to embedding these integrated systems as part of the multi-sector HSCN optimization problem will be more effective and futuristic. The reasoning is to benefit from economy of scale, and it is expected that the integrated systems will help in maximizing the tradeoffs related with energy and carbon emission penalties (Kazi et al., 2015, 2016, 2017, 2018, 2019; Eljack et al., 2019). In the integrated systems problem, the recovery of waste heat and material streams (mainly hydrocarbon by-products) will be the focus in the industrial sector problem and in considering the production of $\mathrm{H}_{2}$ carriers (e.g., ammonia, methanol, etc.). The problem is a multi-objective formulation that will be complex due to the competing objectives: minimizing the cost (CAPEX and OPEX), maximizing $\mathrm{H}_{2}$ production, minimizing carbon emissions, and maximizing the use of renewable energy. In addition, safety in the design of the integrated system should be consider. Of particular relevance is the framework of carbon-hydrogen-oxygen symbiosis network (CHOSYN) recently introduced by Noureldin and El-Halwagi (2015). This framework enables the multi-scale targeting and integration of hydrocarbon processing systems. Several classes of the CHOSYN problem can be used as foundational elements for the framework proposed in this work. Recently, Kazi et al. (in press) have proposed a strategic framework for the design of a hydrogen supply chain network (HSCN) mainly investigating the potential of industrial decarbonization and multi-sectors integration (i.e., transportation, energy, and shipping) via green hydrogen economy. Certainly, the hydrogen production problem has its specific idiosyncrasies and will require the developed of tailored formulations and tools for the effective integration with eco-industrial facility.

\section{Impacts of Intemporal Changes in Hydrogen Prices/Demand/ Global Markets}

Uncertainty is an inseparable part of hydrogen supply chain network. This is because the hydrogen production networks have no matured infrastructure yet and the design of the 
networks is intended to meet potential demands. In that respect, management in the strategy planning horizon faces mainly two forms of uncertainties. First of all, the value of different parameters of the model could not be reliably predicted due to the unavailability of historical data. In addition, the exact limitations of models' restriction cannot be specified by management and decision makers, because of the complex nature of such network design problems. It is worth noting that, despite the importance of the versatility of the restrictions in the hydrogen supply chains, none of the researchers has monitored their impact in the model formulation in the literature (Fazli-Khalaf et al., 2020). These uncertainties may have a significant impact on the unreliability of the results. It can have a major effect on network responsiveness and can contribute to customer demand dissatisfaction due to lack of a sound strategic plan. A new hybrid modeling approach should be built to overcome the noted challenge. It should allow policy makers to simultaneously monitor the complexity of parameters and the flexibility of constraints, which are the key to the design of the hydrogen production networks. It will help to fix one of the key shortcomings in past research on comprehensive hydrogen network design models. Hydrogen as a fuel may be regarded as a significant commodity to be used in people's everyday lives in coming years. Any delay in the delivery of such a strategic product could trigger price volatility and social discontent. The distribution of this commodity to fuel stations on schedule and customer permanent access to hydrogen are therefore very important issues. They affect the desire of customers to use hydrogen vehicles. Thus, the structure and reaction of the hydrogen supply chains should be defined under all possible conditions. The possible sources of such uncertainties could be categorized into strategic uncertainty (i.e., government incentives and policies, hydrogen demand, technology evolution, and feedstock supply), and operational uncertainty (i.e., machine failure, feedstock supply costs, byproducts selling price, and hydrogen selling price fluctuations) (Li et al., 2019).

In HSCN, trade-off between different alternatives is inherent into optimization-based models considering the uncertaintyrelated aspects. Input data uncertainty is usually expressed by discrete scenarios (probability of occurrence), which are considered at once during optimization. However, a large number of these discrete scenarios, which jeopardize compute tractability by the resolution of big-scale models (i.e., models with a large number of variables and limitations) will be expected to accurately represent high levels of uncertainties (i.e., high numbers of elements subject to uncertainty and their correlations). Despite challenging computational aspects, stochastic or data-driven modeling can offer important advancements to the infrastructure of hydrogen supply chain problem (Nunes et al., 2015). Kim et al. (2008) proposed one of the initial stochastic approaches to managing demand volatility, but ignored network growth in long-term planning. Almansoori and Shah (2012) managed to consider the evolution of the network, but the complexity results into long computation times. The cost of ecology, energy and risk for the economic model was considered by Dayhim et al. (2014). All of these past works could manage just a few of the scenarios that are difficult to anticipate in the hydrogen supply chain subject. Modified data or data of other geographical sites can also be used to determine if the model can be updated for an enlarged supply chain of hydrogen. Furthermore, it is important to include environmental costs in the proposed model, as the hydrogen search focused on assuming that the energy was clean.

\section{Role of Policies in Support of a Multi-Sector Global Hydrogen Economy}

A secure and supportive policy framework will be required to facilitate adequate private investment across the whole hydrogen supply chain network (equipment manufacturers, infrastructure providers, and vehicle manufacturers, etc.) to achieve speedy expansion (Hughes and Agnolucci, 2012). Hydrogen demand and infrastructure spending throughout the multi-sector can be stimulated by technology-neutral tools targeted at end users. Such instruments can include carbon price limits, pollution regulations (low-emission regions, emissions standards, or targets), renewable energy content related regulations, or carbon pricing for the particular sectors (Nastasi, 2019). Measures are required in the short term to cover the initial cost gap (partially) with incumbent technologies (Tsai and Mezher, 2020). This refers to fuel cell vehicle (FCEV) applications and to investment in infrastructure. Such incentives (CAPEX subsidies, tax rebates), with a simple phasing-out route, can be aimed at priority technologies and segments (Burandt et al., 2019; Sofia et al., 2020). Upstream, maximum usage of renewable hydrogen production capacity could be encouraged through the promotion of renewable hydrogen certification. Certification schemes may help track power consumption (when connected to the Grid) and further emphasize the systemic added value of electrolysers (Burandt et al., 2019). Moreover, ongoing research, development, and implementation investments are important to continue cutting costs and boost system overall efficiencies, which in turn help reduce end-use hydrogen costs (Nastasi, 2019). Pilot and demonstration projects for full implementation are needed to gain extensive experience with technical, economic and regulatory variables in real world situations.

\section{CONCLUSION AND FUTURE DIRECTIONS}

For decades, hydrogen has been a feedstock in a variety of main sectors of the industry. Hydrogen may be the "missing link" to provide high volumes of renewable energy for multiple sectors, which would otherwise have trouble decarbonizing via direct electrification, such as transportation, industry, and current use of natural gas. Hydrogen economy can foster the energy transition by having a united and long-term ambition of accelerating significant investment in the development and commercialization of the low carbon hydrogen applications, while facilitating the integration among multiple sectors (e.g., industry, electricity system, buildings, transport, and global trading). Hydrogen may potentially be used to transport renewable energy over long distances. Regions with ample and inexpensive sources of renewable energy may generate hydrogen for transport to regions with limitable capacity or higher 
production costs of renewable power generation. Renewable energy transportation by hydrogen could be built on different levels, from local to international. Progressive implementation of hydrogen end-use applications will require collaborative efforts for hydrogen production, storage, transportation, and distribution across multiple sectors. The technology is available, and a rapid increase is now required for cost savings and the economic viability of hydrogen as a long-term facilitator of the energy transition. The initial efforts should be focused on large scale applications that are able to generate rapidly large-scale economies, have minimal infrastructural needs, and are the best performing solution in sectors. In this regards, large industry (refineries, chemicals facilities, methanol production) and heavyduty transport (large fleets of hydrogen buses, trucks, trains on non-electrified lines, and maritime, etc.) will be ideal starting point, where renewable hydrogen is a good solution for achieving climatic objectives. It is evident that compared to fossil fuel industries, there will be significant investment in facilities to provide end-users with clean hydrogen. The recent steep decline in energy costs from renewables makes it feasible.

First of all, to flourish multi-sector integrated HSCN needs very low cost and abundance of renewables, which are already available in the Middle East, North Africa, Mexico, Chile, Australia, and the North Sea, etc. Clean hydrogen has the potential to be traded as a new commodity. Global natural gas providers such as Canada, Iran, Norway, Qatar, Russia, and the US that invest in carbon capture technologies can leverage their investments by venturing into blue $\mathrm{H}_{2}$ production. Other market possibilities arise in regions like the Middle East and North Africa mainly to the low cost of producing hydrogen in remote desert locations and shipping it to global markets. This would follow in the footstep of countries like Argentina, Australia, Chile, and China. Hence, a move toward a hydrogen economy using integrated systems (including renewable energy) can offer energy providing nations an opportunity to reduce to their global emission. Nonetheless there are challenges that

\section{REFERENCES}

Abdin, Z., and Mérida, W. (2019). Hybrid energy systems for off-grid power supply and hydrogen production based on renewable energy: a techno-economic analysis. Energy Convers. Manage 196, 1068-1079. doi: 10.1016/j.enconman.2019.06.068

Abe, J. O., Popoola, A. P. I., Ajenifuja, E., and Popoola, O. M. (2019). Hydrogen energy, economy and storage: review and recommendation. Int. J. Hydrogen Energy 44, 15072-15086. doi: 10.1016/j.ijhydene.2019.04.068

Al-Fadhli, F. M., Baaqeel, H., and El-Halwagi, M. M. (2019). Modular design of carbon-hydrogen-oxygen symbiosis networks over a time horizon with limited natural resources. Chem. Eng. Process. Process Intensif. 141:107535. doi: 10.1016/j.cep.2019.107535

Al-Haidous, S., Msakni, M. K., and Haouari, M. (2016). Optimal planning of liquefied natural gas deliveries. Transp. Res. C Emerg. Technol. 69, 79-90. doi: 10.1016/j.trc.2016.05.017

Almansoori, A., and Betancourt-Torcat, A. (2016). Design of optimization model for a hydrogen supply chain under emission constraints - a case study of Germany. Energy 111, 414-429. doi: 10.1016/j.energy.2016.05.123

Almansoori, A., and Shah, N. (2009). Design and operation of a future hydrogen supply chain: multi-period model. Int. J. Hydrogen Energy 34, 7883-7897. doi: 10.1016/j.ijhydene.2009.07.109 must be addressed related to the transportation of hydrogen. Hydrogen transportation requires liquefaction, which energy intensive; while the alternative of hydrogen conversion into other carriers, such as ammonia, methanol, or organic liquid hydrogen is limited by the significant losses in yields. Secondly, scaling up is required to reduce the costs of hydrogen production (e.g., hundreds of megawatts to gigawatts). Third, the longterm contractual agreements to de-invest the risk of the local downstream clients (large industrial or large-scale mobility deployment) should be guaranteed early. Finally, the integration and evaluation of multi-sector hydrogen supply chain in decarbonization scenarios must be seen as part of a wider shift to global energy and an alternative for energy system designs. Considering the above facts and industrial portfolio of Qatar it can be estimated that futuristic plan for multi-sector hydrogen economy via industrial symbiosis can place Qatar once again as the global hub for clean energy $\left(\mathrm{H}_{2}\right)$. The positive societal impacts will many: booming economy, expanding job market and the supporting services that comes with it. The scope of this paper is to show the potentiality of becoming a global supplier of green hydrogen. However, the detail of developing such multisector global symbiosis for green $\mathrm{H} 2$ economy in Qatar can be explored further.

\section{AUTHOR CONTRIBUTIONS}

FE and M-KK contributed equally to the design and implementation of the research, and to the writing of the manuscript. FE supervised the project. Both authors contributed to the article and approved the submitted version.

\section{FUNDING}

This paper was made possible by NPRP grant no. 10-0205170347 from the Qatar National Research Fund (a member of Qatar Foundation).
Almansoori, A., and Shah, N. (2012). Design and operation of a stochastic hydrogen supply chain network under demand uncertainty. Int. J. Hydrogen Energy 37, 3965-3977. doi: 10.1016/j.ijhydene.2011.11.091

Al-Nouss, A., and Eljack, F. (2019). "Techno-economic-environmental study for recovery of novel water source within a power plant - desalination complex," in The 29th European Symposium on Computer-Aided Process Engineering (ESCAPE-29), eds A. A. Kiss, E. Zondervan, R. Lakerveld, and L. Özkan (Eindhoven: Elsevier), 307-312. doi: 10.1016/B978-0-12-818634-3.50052-7

Al-shanini, A., Ahmad, A., and Khan, F. (2014). Accident modelling and safety measure design of a hydrogen station. Int. J. Hydrogen Energy 39, 20362-20370. doi: 10.1016/j.ijhydene.2014.05.044

Armijo, J., and Philibert, C. (2020). Flexible production of green hydrogen and ammonia from variable solar and wind energy: case study of chile and argentina. Int. J. Hydrogen Energy 45, 1541-1558. doi: 10.1016/j.ijhydene.2019.11.028

Bulletin, F. C. (2020). DNV GL says oil \& gas industry sees hydrogen as key to decarbonisation. Fuel Cells Bull. 2020:13. doi: 10.1016/S1464-2859(20) 30258-3

Burandt, T., Xiong, B., Löffler, K., and Oei, P.-Y. (2019). Decarbonizing China's energy system - modeling the transformation of the electricity, transportation, heat, and industrial sectors. Appl. Energy 255:113820. doi: 10.1016/j.apenergy.2019.113820 
Costantini, V., Crespi, F., Marin, G., and Paglialunga, E. (2017). Eco-innovation, sustainable supply chains and environmental performance in European industries11We gratefully acknowledge the support by the European Union's Horizon 2020 research and innovation programme under grant agreement No. 649186 - ISIGrowth. The comments and suggestions by three anonymous referees are also acknowledged. The usual disclaimers apply. J. Clean. Prod. 155, 141-154. doi: 10.1016/j.jclepro.2016.09.038

Dawood, F., Anda, M., and Shafiullah, G. M. (2020). Hydrogen production for energy: an overview. Int. J. Hydrogen Energy 45, 3847-3869. doi: 10.1016/j.ijhydene.2019.12.059

Dayhim, M., Jafari, M. A., and Mazurek, M. (2014). Planning sustainable hydrogen supply chain infrastructure with uncertain demand. Int. J. Hydrogen Energy 39, 6789-6801. doi: 10.1016/j.ijhydene.2014.02.132

DiRenzo, J. (2019). IMO 2020: Hydrogen's future in maritime. MarineLink. Available online at: https://www.marinelink.com/news/imo-hydrogensfuture-maritime-467713 (accessed September 30, 2020).

DNV GL (2017). Forecast to 2050. Energy Transition Outlook 2017. Available online at: https://eto.dnvgl.com/2017/maritime (accessed September 30, 2020).

Domínguez-García, S., Gutiérrez-Antonio, C., De Lira-Flores, J. A., Ponce-Ortega, J. M., and El-Halwagi, M. M. (2017). Strategic planning for the supply chain of aviation biofuel with consideration of hydrogen production. Ind. Eng. Chem. Res. 56, 13812-13830. doi: 10.1021/acs.iecr.7b02632

Edelia, E. M., Winkler, R., Sengupta, D., El-Halwagi, M. M., and Mannan, M. S. (2018). A computational fluid dynamics evaluation of unconfined hydrogen explosions in high pressure applications. Int. J. Hydrogen Energy 43, 16411-16420. doi: 10.1016/j.ijhydene.2018.06.108

El-Halwagi, M. M. (2017). A shortcut approach to the multi-scale atomic targeting and design of $\mathrm{C}-\mathrm{H}-\mathrm{O}$ symbiosis networks. Process Integr. Optimiz. Sust. 1, 3-13. doi: 10.1007/s41660-016-0001-y

El-Halwagi, M. M., and Campbell, J. E. (2018). Integrated and tunable system for the production of syngas and chemicals via solar-assisted electrolysis and combined reforming. WIPO IP, US patent application, Geneva, Switzerland.

Eljack, F., and Kazi, M.-K. (2016). Process safety and abnormal situation management. Curr. Opin. Chem. Eng. 14, 35-41. doi: 10.1016/j.coche.2016.07.004

Eljack, F., Kazi, M.-K., and Kazantzi, V. (2019). Inherently safer design tool (iSDT): a property-based risk quantification metric for inherently safer design during the early stage of process synthesis. J. Loss Prev. Process Ind. 57, 280-290. doi: 10.1016/j.jlp.2018.12.004

Fazli-Khalaf, M., Naderi, B., Mohammadi, M., and Pishvaee, M. S. (2020). Design of a sustainable and reliable hydrogen supply chain network under mixed uncertainties: a case study. Int. J. Hydrogen Energy. 45, 34503-34531. doi: 10.1016/j.ijhydene.2020.05.276

Gençer, E., and Agrawal, R. (2017). Strategy to synthesize integrated solar energy coproduction processes with optimal process intensification. Case study: efficient solar thermal hydrogen production. Comput. Chem. Eng. 105, 328-347. doi: 10.1016/j.compchemeng.2017.01.038

Gulf Times (2018). Qatar has recently submitted an application to join IMO. Gulf Times Newspaper. Available online at: https://www.gulf-times.com/ story/613701/Qatar-submits-candidature-to-join-IMO-top-body (accessed September 30, 2020).

Han, U., Oh, J., and Lee, H. (2018). Safety investigation of hydrogen charging platform package with CFD simulation. Int. J. Hydrogen Energy 43, 13687-13699. doi: 10.1016/j.ijhydene.2018.05.116

Helgeson, B., and Peter, J. (2020). The role of electricity in decarbonizing European road transport - development and assessment of an integrated multi-sectoral model. Appl. Energy 262:114365. doi: 10.1016/j.apenergy.2019. 114365

Hughes, N., and Agnolucci, P. (2012). "4.03 - hydrogen economics and policy,” in Comprehensive Renewable Energy, ed A. Sayigh (Oxford: Elsevier), 65-95. doi: 10.1016/B978-0-08-087872-0.00417-0

Hydrogen Council (2017). Hydrogen Scaling Up - A Sustainable Pathway for the Global Energy Transition. Available online at: https://hydrogencouncil.com/ wp-content/uploads/2017/11/Hydrogen-scaling-up-Hydrogen-Council.pdf (accessed September 30, 2020).

IEA (2019a). The Future of Hydrogen - Seizing Today's Opportunities. Technology Report. Available online at: https://www.iea.org/reports/the-futureof-hydrogen (accessed September 30, 2020).
IEA (2019b). World Energy Outlook 2019. Flagship Report. Available online at: https://www.iea.org/reports/world-energy-outlook-2019 (accessed September 30, 2020).

IRENA (2019). Renewable Power Generation Costs in 2018. Abu Dhabi: International Renewable Energy Agency.

Ishaq, H., and Dincer, I. (2019). Analysis and optimization for energy, cost and carbon emission of a solar driven steam-autothermal hybrid methane reforming for hydrogen, ammonia and power production. J. Clean. Prod. 234, 242-257. doi: 10.1016/j.jclepro.2019.06.027

Juárez-García, M., Ponce-Ortega, J. M., and El-Halwagi, M. M. (2019). A disjunctive programming approach for optimizing carbon, hydrogen, and oxygen symbiosis networks. Process Integr. Optimiz. Sust. 3, 199-212. doi: $10.1007 / \mathrm{s} 41660-018-0065-y$

Kawasaki (2019). Large scale LH2 supply chain project \& H2 gas turbine demonstration. Hydrogen Safety - Liquid Hydrogen (LH2) Workshop. Available online at: https://www.sintef.no/globalassets/sintef-industri/arrangement/ hydrogen-safety-2019/11_large-scale-lh2-supply-chain-project--h2-gasturbine-demonstration_k_morimoto_kawasaki_hi.pdf/ (accessed September 30, 2020).

Kayfeci, M., Keçebaş, A., and Bayat, M. (2019). "Chapter 3 - hydrogen production,” in Solar Hydrogen Production, eds F. Calise, M. D. D'Accadia, M. Santarelli, A. Lanzini, and D. Ferrero (Cambridge, MA: Academic Press), 45-83. doi: 10.1016/B978-0-12-814853-2.00003-5

Kazi, M.-K., Eljack, F., Al-Sobhi, S. A., Kazantzis, N., and Kazantzi, V. (2019). Application of i-SDT for safer flare management operation. Process Saf. Environ. Protect. 132, 249-264. doi: 10.1016/j.psep.2019.10.023

Kazi, M.-K., Eljack, F., Amanullah, M., AlNouss, A., and Kazantzi, V. (2018). A process design approach to manage the uncertainty of industrial flaring during abnormal operations. Comput. Chem. Eng. 117, 191-208. doi: 10.1016/j.compchemeng.2018.06.011

Kazi, M.-K., Eljack, F., El-Halwagi, M. M., and Haouari, M. (in press). Green hydrogen for industrial sector decarbonization: costs and impacts on hydrogen economy in qatar. Comput. Chem. Eng. 107144. doi: 10.1016/j.compchemeng.2020.107144

Kazi, M.-K., Eljack, F., Elsayed, N. A., and El-Halwagi, M. M. (2016). Integration of energy and wastewater treatment alternatives with process facilities to manage industrial flares during normal and abnormal operations: multiobjective extendible optimization framework. Ind. Eng. Chem. Res. 55, 2020-2034. doi: 10.1021/acs.iecr.5b03938

Kazi, M.-K., Eljack, F., and Kazantzi, V. (2017). "Managing uncertain industrial flares during abnormal process operations using an integrated optimization and monte carlo simulation approach," in 27th European Symposium on Computer Aided Process Engineering, Vol. 40, eds A. Espuña,M. Graells, and L. Puigjaner (Barcelona: Elsevier), 2425-2430. doi: 10.1016/B978-0-444-63965-3.50406-2

Kazi, M.-K., Mohammed, F., AlNouss, A. M. N., and Eljack, F. (2015). Multiobjective optimization methodology to size cogeneration systems for managing flares from uncertain sources during abnormal process operations. Comput. Chem. Eng. 76, 76-86. doi: 10.1016/j.compchemeng.2015.02.012

Ketabchi, E., Mechleri, E., and Arellano-Garcia, H. (2019). Increasing operational efficiency through the integration of an oil refinery and an ethylene production plant. Chem. Eng. Res. Des. 152, 85-94. doi: 10.1016/j.cherd.2019.09.028

Khatri, N., and Khatri, K. K. (2020). Hydrogen enrichment on diesel engine with biogas in dual fuel mode. Int. J. Hydrogen Energy 45, 7128-7140. doi: 10.1016/j.ijhydene.2019.12.167

Kim, J., Chung, B. D., Kang, Y., and Jeong, B. (2018). Robust optimization model for closed-loop supply chain planning under reverse logistics flow and demand uncertainty. J. Clean. Prod. 196, 1314-1328. doi: 10.1016/j.jclepro.2018.06.157

Kim, J., Lee, Y., and Moon, I. (2008). Optimization of a hydrogen supply chain under demand uncertainty. Int. J. Hydrogen Energy 33, 4715-4729. doi: 10.1016/j.ijhydene.2008.06.007

Lasn, K., and Echtermeyer, A. T. (2014). Safety approach for composite pressure vessels for road transport of hydrogen. Part 1: acceptable probability of failure and hydrogen mass. Int. J. Hydrogen Energy 39, 14132-14141. doi: 10.1016/j.ijhydene.2014. 06.116

Lee, W.-S., Oh, H.-T., Lee, J.-C., Oh, M., and Lee, C.-H. (2019). Performance analysis and carbon reduction assessment of an integrated syngas purification process for the co-production of hydrogen and power in 
an integrated gasification combined cycle plant. Energy 171, 910-927. doi: 10.1016/j.energy.2019.01.069

Li, L., Manier, H., and Manier, M.-A. (2019). Hydrogen supply chain network design: an optimization-oriented review. Renew. Sust. Energy Rev. 103, 342-360. doi: 10.1016/j.rser.2018.12.060

Liu, H., Qu, J., Pan, M., Zhang, B., Chen, Q., and He, C. (2019). Design and optimization of small-scale methanol production from sour natural gas by integrating reforming with hydrogenation. Int. J. Hydrogen Energy. 45, 34483-34493. doi: 10.1016/j.ijhydene.2019.11.229

Mirza, N. R., Degenkolbe, S., and Witt, W. (2011). Analysis of hydrogen incidents to support risk assessment. Int. J. Hydrogen Energy 36, 12068-12077. doi: 10.1016/j.ijhydene.2011.06.080

Moreno-Benito, M., Agnolucci, P., and Papageorgiou, L. G. (2017). Towards a sustainable hydrogen economy: optimisation-based framework for hydrogen infrastructure development. Comput. Chem. Eng. 102, 110-127. doi: 10.1016/j.compchemeng.2016.08.005

Mosca, L., Medrano Jimenez, J. A., Wassie, S. A., Gallucci, F., Palo, E., Colozzi, M., et al. (2020). Process design for green hydrogen production. Int. J. Hydrogen Energy 45, 7266-7277. doi: 10.1016/j.ijhydene.2019.08.206

Msakni, M. K., and Haouari, M. (2018). Short-term planning of liquefied natural gas deliveries. Transp. Res. C Emerg. Technol. 90, 393-410. doi: 10.1016/j.trc.2018.03.013

Nastasi, B. (2019). "Chapter 2 - hydrogen policy, market, and R\&D projects," in Solar Hydrogen Production, eds F. Calise, M. D. D’Accadia, M. Santarelli, A. Lanzini, and D. Ferrero (Cambridge, MA: Academic Press), 31-44. doi: 10.1016/B978-0-12-814853-2.00002-3

Nguyen, T., Abdin, Z., Holm, T., and Mérida, W. (2019). Grid-connected hydrogen production via large-scale water electrolysis. Energy Convers. Manage. 200:112108. doi: 10.1016/j.enconman.2019.112108

Noureldin, M. M. B., and El-Halwagi, M. M. (2015). Synthesis of C-H-O symbiosis networks. AIChE J. 61, 1242-1262. doi: 10.1002/aic.14714

Nunes, P., Oliveira, F., Hamacher, S., and Almansoori, A. (2015). Design of a hydrogen supply chain with uncertainty. Int. J. Hydrogen Energy 40, 16408-16418. doi: 10.1016/j.ijhydene.2015.10.015

Ochoa Bique, A., and Zondervan, E. (2018). An outlook towards hydrogen supply chain networks in 2050 - design of novel fuel infrastructures in Germany. Chem. Eng. Res. Des. 134, 90-103. doi: 10.1016/j.cherd.2018. 03.037

Oliveira, M. T., Reis, L. H. A., Medeiros, D. S. V., Carrano, R. C., Olabarriaga, S. D., and Mattos, D. M. F. (2020). Blockchain reputation-based consensus: a scalable and resilient mechanism for distributed mistrusting applications. Comput. Netw. 179:107367. doi: 10.1016/j.comnet.2020.107367

Panu, M., Topolski, K., Abrash, S., and El-Halwagi, M. M. (2019). $\mathrm{CO}_{2}$ footprint reduction via the optimal design of carbon-hydrogenoxygen symbiosis networks (CHOSYNs). Chem. Eng. Sci. 203, 1-11. doi: $10.1016 /$ j.ces.2019.03.066

Peninsula (2020). Qatar to build 800 MW solar power plant on $10 \mathrm{sqkm}$ plot. The Peninsula Newspaper. Available online at: https://thepeninsulaqatar.com/ article/19/01/2020/Qatar-to-build-800-MW-solar-power-plant-on-10-sqkmplot (accessed September 30, 2020)

Phull, B. (2003). "Evaluating hydrogen embrittlement," in Corrosion: Fundamentals, Testing, and Protection, eds S. D. Cramer and B. S. Jr. Covino (Novelty, OH: ASM International). 617-623.

Pozzi, S. (2017). Hydrogen Fuel Safety: Essential Facts for Transit Operators. BALLARD Available online at: https://blog.ballard.com/hydrogen-fuel-safety (accessed September 30, 2020).

QSNDS (2018). Qatar Second National Development Strategy 2018-2022. Available online at: http://extwprlegs1.fao.org/docs/pdf/qat181692E.pdf (accessed September 30, 2020).

Salem, R. W., and Haouari, M. (2017). A simulation-optimisation approach for supply chain network design under supply and demand uncertainties. Int. J. Prod. Res. 55, 1845-1861. doi: 10.1080/00207543.2016. 1174788
Schmidtchen, U. (2009). "FUELS - SAFETY | hydrogen: overview," in Encyclopedia of Electrochemical Power Sources, ed J. Garche (Amsterdam: Elsevier), 519-527. doi: 10.1016/B978-044452745-5.00842-X

Seo, S.-K., Yun, D.-Y., and Lee, C.-J. (2020). Design and optimization of a hydrogen supply chain using a centralized storage model. Appl. Energy 262:114452. doi: 10.1016/j.apenergy.2019.114452

Shiva Kumar, S., and Himabindu, V. (2019). Hydrogen production by PEM water electrolysis - a review. Mater. Sci. Energy Technol. 2, 442-454. doi: 10.1016/j.mset.2019.03.002

Singh, S., Jain, S., Ps, V., Tiwari, A. K., Nouni, M. R., Pandey, J. K., et al. (2015). Hydrogen: a sustainable fuel for future of the transport sector. Renew. Sust. Energy Rev. 51, 623-633. doi: 10.1016/j.rser.2015.06.040

SINTEF (2019). ELEGANCY Dutch Case Study: TNO Initiates Industrial Participation with H-Vision Project. SINTEFblog Available online at: https:// blog.sintef.com/sintefenergy/elegancy-tno-h-vision-project/ (accessed September 30, 2020).

Sofia, D., Gioiella, F., Lotrecchiano, N., and Giuliano, A. (2020). Cost-benefit analysis to support decarbonization scenario for 2030: a case study in Italy. Energy Policy 137:111137. doi: 10.1016/j.enpol.2019.111137

Spallina, V., Motamedi, G., Gallucci, F., and van Sint Annaland, M. (2019). Techno-economic assessment of an integrated high pressure chemicallooping process with packed-bed reactors in large scale hydrogen and methanol production. Int. J. Greenh. Gas Control 88, 71-84. doi: 10.1016/j.ijggc.2019.05.026

Talebian, H., Herrera, O. E., and Mérida, W. (2019). Spatial and temporal optimization of hydrogen fuel supply chain for light duty passenger vehicles in British Columbia. Int. J. Hydrogen Energy 44, 25939-25956. doi: 10.1016/j.ijhydene.2019.07.218

The Maritime Executive (2018). Blueprint Prepared for Australia's Hydrogen Trade. Available online at: https://www.maritime-executive.com/article/blueprintprepared-for-australia-s-hydrogen-trade (accessed September 30, 2020).

Tlili, O., Mansilla, C., Linßen, J., Reu,ß, M., Grube, T., Robinius, M., et al. (2020) Geospatial modelling of the hydrogen infrastructure in France in order to identify the most suited supply chains. Int. J. Hydrogen Energy 45, 3053-3072. doi: 10.1016/j.ijhydene.2019.11.006

Tsai, I. T., and Mezher, T. (2020). Rationalizing energy policy reforms in the gulf cooperation council: Implications from an institutional analysis. Energy Policy 142:111545. doi: 10.1016/j.enpol.2020.111545

van der Roest, E., Snip, L., Fens, T., and van Wijk, A. (2020). Introducing power-to-H3: combining renewable electricity with heat, water and hydrogen production and storage in a neighbourhood. Appl. Energy 257:114024. doi: 10.1016/j.apenergy.2019.114024

Zareei, J., and Rohani, A. (2020). Optimization and study of performance parameters in an engine fueled with hydrogen. Int. J. Hydrogen Energy 45, 322-336. doi: 10.1016/j.ijhydene.2019.10.250

Zhang, C., Nguyen, C., Eljack, F., Linke, P., and El-Halwagi, M. M. (2018). Integration of safety in the optimization of transporting hazardous materials. Process Integr. Optimiz. Sustain. 2, 435-446. doi: 10.1007/s41660-018-0063-0

Zhou, X., Zhang, H., Qiu, R., Lv, M., Xiang, C., Long, Y., et al. (2019). A twostage stochastic programming model for the optimal planning of a coal-toliquids supply chain under demand uncertainty. J. Clean. Prod. 228, 10-28. doi: 10.1016/j.jclepro.2019.04.264

Conflict of Interest: The authors declare that the research was conducted in the absence of any commercial or financial relationships that could be construed as a potential conflict of interest.

Copyright (C) 2021 Eljack and Kazi. This is an open-access article distributed under the terms of the Creative Commons Attribution License (CC BY). The use, distribution or reproduction in other forums is permitted, provided the original author(s) and the copyright owner(s) are credited and that the original publication in this journal is cited, in accordance with accepted academic practice. No use, distribution or reproduction is permitted which does not comply with these terms. 